\title{
Friction Stir Lap Welding of Magnesium Alloy and Zinc-Coated Steel
}

\author{
Y. C. Chen* and K. Nakata \\ Joining and Welding Research Institute, Osaka University, Ibaraki 567-0047, Japan
}

AZ31 Mg alloy and zinc-coated steel were lap welded using friction stir welding technology. The microstructures and mechanical properties of the joints were examined. The lap shear tensile test results showed that the welding speed had a significant effect on the failure loads of the joints at the rotation speed of $1500 \mathrm{rpm}$. The maximum failure loads of $3.4 \mathrm{kN}, 65 \%$ of that of the zinc-coated steel base material, could be obtained when the welding speed was $150 \mathrm{~mm} / \mathrm{min}$. Microstructure analysis showed that the intervention of zinc coat promoted the formation of $\mathrm{Mg}-\mathrm{Zn}$ low-melting-point eutectic structure at the interface. The joining mechanism and the role of $\mathrm{Zn}$ coat on friction stir lap welding of Mg alloy and zinc-coated steel were put forward. [doi:10.2320/matertrans.M2009022]

(Received May 20, 2009; Accepted August 26, 2009; Published October 25, 2009)

Keywords: welding, mechanical properties, microstructure, metals

\section{Introduction}

Magnesium alloys, the lightest of the structural metals, with a density two-thirds that of aluminum alloy are a promising structural material in vehicle fabrication. Zinccoated steel with excellent corrosion resistance and good durability is a promising structural material in vehicle applications. In order to achieve combined properties of magnesium alloys and zinc-coated steel, development of reliable joints between magnesium alloy and zinc-coated steel is necessary. As a solid state welding technology, friction stir welding (FSW) process ${ }^{1)}$ can be used to join Mg alloys ${ }^{2-6)}$ and steel ${ }^{7-14)}$ and gets high quality joints than fusion welding technology. Such good merits are also expected for joining dissimilar metal materials. Watanabe et $\left.a l .{ }^{15}\right)$ studied the weldability of FSW AZ31 magnesium alloy/SS400 steel, and reported that the rotation speed, the position of the pin axis had a significant effect on the strength and the microstructure of the joint. The maximum tensile strength of a butt joint reached about $70 \%$ of that of the magnesium base metal and the fracture path was along the joint interface. Liu et al. ${ }^{16)}$ studied the lap joining of the dissimilar alloys of AZ31B Mg alloy and 304 steel by a laser-GTA hybrid welding technique. A transitional zone formed at the interface of the $\mathrm{Mg}-\mathrm{Fe}$ during laser-GTA hybrid welding and $\mathrm{Mg}$ diffused into the matrix of $\mathrm{Fe}$ in the form of oxides and reacted in the transitional zone. During tensile testing, the joints fractured at the interface between the Mg alloy and the steel. The metallic oxides produced at the $\mathrm{Mg}-\mathrm{Fe}$ interface deteriorated the mechanical properties of the joints.

Up to date, current studies only report the weldability of FSW or a laser-GTA hybrid welding of magnesium alloy/ steel and the preliminary results of mechanical properties and microstructure evolution of the joints. ${ }^{15,16)}$ Investigations on FSW of magnesium alloy and zinc-coated steel have not yet been reported. The object of the present study is to examine microstructure evolution and mechanical properties in FSW magnesium alloy and zinc-coated steel.

In this study, AZ31 magnesium alloy and low carbon zinccoated steel are selected for friction stir lap welding. The

*Corresponding author, E-mail: armstrong@hit.edu.cn magnesium alloy sheet is put on the zinc-coated steel sheet. The inserting depth of the tool, being strictly controlled, is less than the thickness of the magnesium alloy. That is, the probe tip of the tool does not reach the surface of the zinccoated steel sheet during welding. The emphasis is to study the interface microstructure evolution and clarify the joining mechanism.

\section{Experimental Procedures}

The base materials used in this study were a 1.6-mm-thick AZ31 magnesium alloy sheet and a 0.8 -mm-thick low carbon zinc-coated steel sheet. The chemical compositions and mechanical properties of the base materials are shown in Table 1. Rectangular welding samples, $300 \mathrm{~mm}$ long by $100 \mathrm{~mm}$ wide, were lap-welded using a FSW machine. After a series of feasibility tests, the following experimental parameters were selected in this study. The welding parameters are the rotation speed of $1500 \mathrm{rpm}$ and the welding speed of $100-300 \mathrm{~mm} / \mathrm{min}$. The working load of the welding tool (made of SKD61 tool steel) is $3.92 \mathrm{kN}$. The shoulder diameter and probe diameter of the tool are $15 \mathrm{~mm}$ and $5 \mathrm{~mm}$, respectively. The length of the probe is $1.5 \mathrm{~mm}$ and the welding tilt angle is $3^{\circ}$.

After welding, the joint was cross-sectioned perpendicular to the welding direction for metallographic analysis and lap shear tensile tests using an electrical-discharge cutting machine. The cross-sections of the metallographic specimens were mechanically ground with water abrasive paper and polished with $3 \mu \mathrm{m}$ and $1 \mu \mathrm{m}$ diamond, then observed by optical microscopy (OM). The mechanical properties of the joint were measured using tensile tests. The tensile tests were carried out at room temperature at a crosshead speed of $1 \mathrm{~mm} / \mathrm{min}$ using a tensile testing machine, and the mechanical properties of the joint were evaluated using three tensile specimens cutting from the same joint. The shape of the test specimen is rectangular and the width of each specimen is $20 \mathrm{~mm}$.

The welding thermal cycle histories along the interface during FSW were measured with an array of K-type thermocouples $(0.2 \mathrm{~mm}$ diameter $)$ at various locations from the weld center. Microstructure characteristic and element distribution along the interface were analyzed by scanning 
Table 1 Chemical compositions and mechanical properties of base materials.

\begin{tabular}{|c|c|c|c|c|c|c|c|c|c|c|c|c|}
\hline \multirow{2}{*}{ Base materials } & \multicolumn{10}{|c|}{ Chemical compositions (mass\%) } & \multicolumn{2}{|c|}{ Mechanical properties } \\
\hline & $\mathrm{Al}$ & $\mathrm{Cu}$ & $\mathrm{Mn}$ & $\mathrm{Fe}$ & $\mathrm{C}$ & $\mathrm{Mg}$ & $\mathrm{Ni}$ & $\mathrm{P}$ & $\mathrm{Zn}$ & $S$ & Strength, $\sigma / \mathrm{MPa}$ & Elongation, $\delta / \%$ \\
\hline AZ31 & 3 & - & 0.2 & - & - & Bal. & - & - & 1 & - & 239 & 13 \\
\hline
\end{tabular}
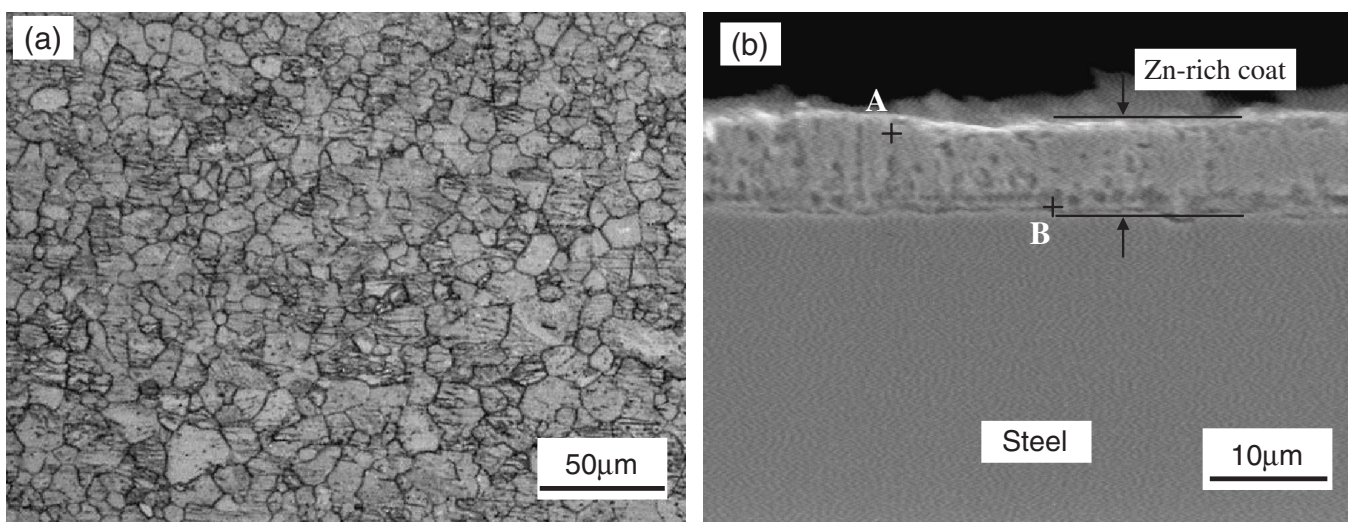

Fig. 1 Microstructure of the base material. (a) AZ31 magnesium alloy and (b) zinc-coated steel.
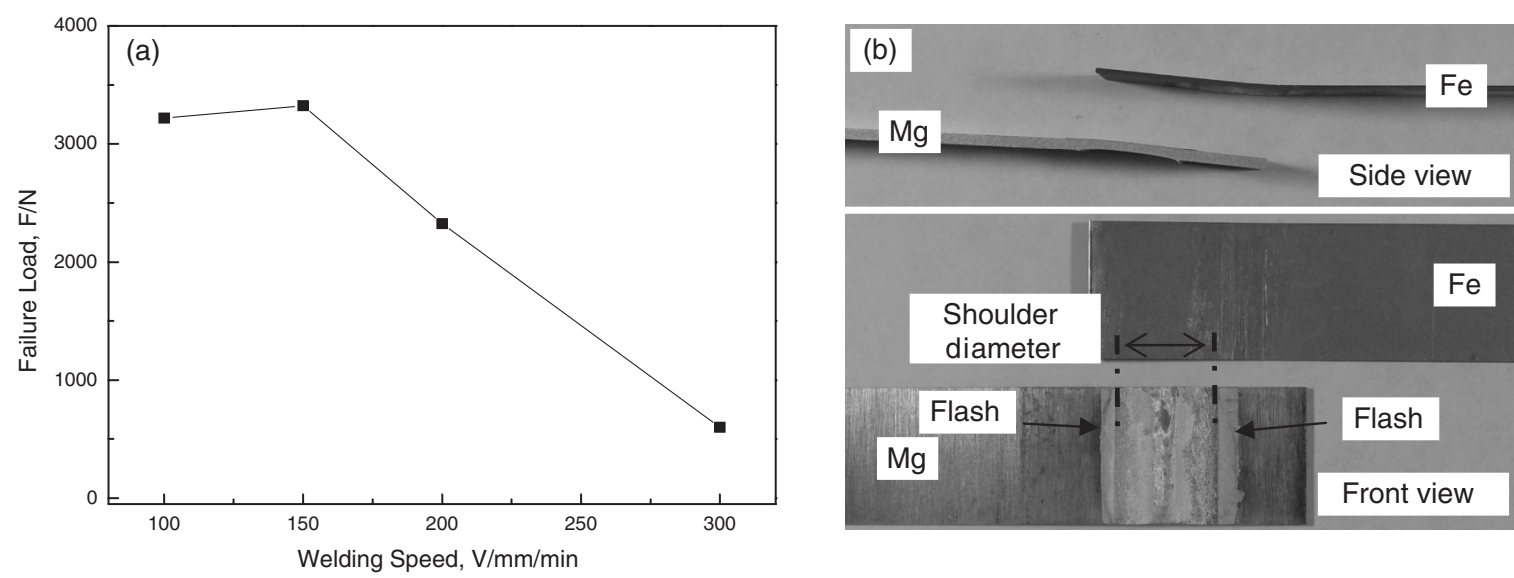

Fig. 2 Failure loads and fracture locations of the joints. (a) Failure loads and (b) a typical fracture location.

electron microscopy (SEM) equipped with an energydispersive X-ray spectroscopy (EDS) analysis system. Fracture surfaces of joints were analyzed using X-ray diffraction (XRD) after tensile test.

\section{Results and Discussion}

Figure 1 shows the microstructure of the base materials (BM). AZ31 BM has a roughly equiaxed grain structure with grain size from $10 \mu \mathrm{m}$ to $15 \mu \mathrm{m}$. Figure 1(b) shows the microstructure near the zinc coat surface of zinc-coated steel. It can be seen that the $\mathrm{Zn}$ coat is about $10 \mu \mathrm{m}$ thick. The chemical composition (at\%) of points $\mathrm{A}$ and $\mathrm{B}$ are $75.06 \% \mathrm{Zn}-20.73 \% \mathrm{Fe}-4.21 \% \mathrm{Al}$ and $62.91 \% \mathrm{Zn}-34.95 \% \mathrm{Fe}-$ $2.15 \% \mathrm{Al}$, respectively. The dominant element in $\mathrm{Zn}$ coat is zinc and iron. Moreover, the content of zinc increases close to the surface of the layer. That is to say, the composition of the layer progressively approaches pure zinc from the interface to the surface.
Figure 2 shows the failure loads and fracture locations of the joints. The lap shear tensile test results show that the welding speed has a significant effect on the tensile strengths of $\mathrm{Mg}$ alloy and zinc-coated steel friction stir lap joints at the rotation speed of $1500 \mathrm{rpm}$. The maximum failure loads of $3.4 \mathrm{kN}, 65 \%$ of that of zinc-coated steel BM, can be obtained when the welding speed is $150 \mathrm{~mm} / \mathrm{min}$. With the increasing welding speeds, the failure loads of the joints decrease. It means high-strength $\mathrm{Mg}$ and zinc-coated steel friction stir lap joints can be obtained when the appropriate welding parameters are selected. Figure 2(b) shows the fracture locations of the joints. All the joints fracture at the interface. It should be mentioned that the front view of the fracture surface at the side of $\mathrm{Mg}$ presents a special feature. The width of the joining region obviously exceeds the width of the probe diameter, even the shoulder diameter. A heavy flash of resolidification was observed at the edge of the joining region.

Figure 3 shows the fracture surface of the joints produced at different welding speeds. It can be seen from the width of 

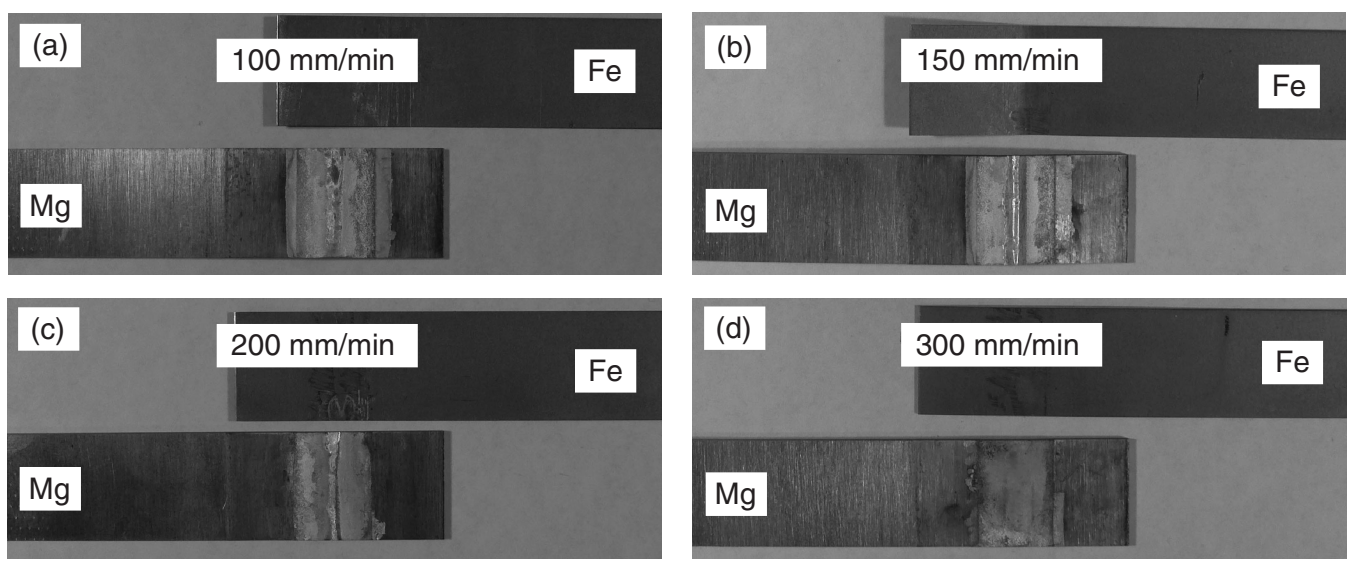

Fig. 3 The front view of fracture surface of the joints at different welding speeds. (a) $100 \mathrm{~mm} / \mathrm{min}$, (b) $150 \mathrm{~mm} / \mathrm{min}$, (c) $200 \mathrm{~mm} / \mathrm{min}$ and (d) $300 \mathrm{~mm} / \mathrm{min}$.

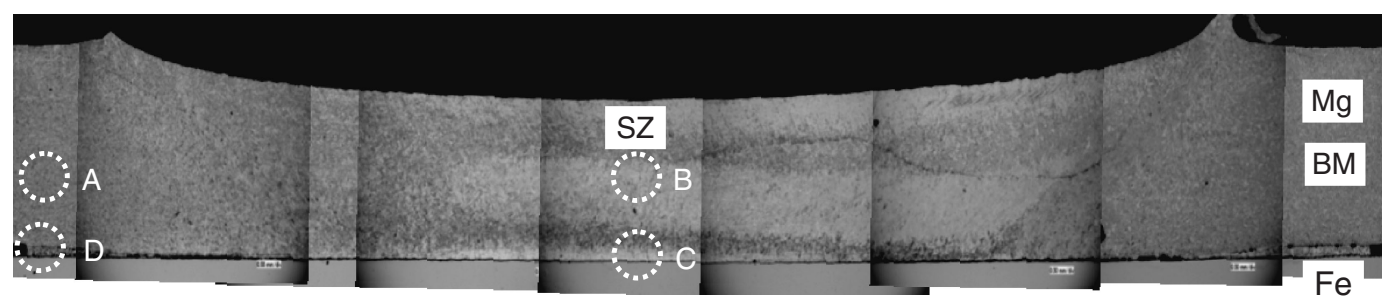

Fig. 4 A typical cross-section of the lap joint.

joining area and the characteristic of the fracture surface that the welding speed has a significant effect on the joining status of $\mathrm{Mg}$ alloy and zinc-coated steel. With the increasing welding speed, the width of joining area significantly decreases. With regards to the characteristic of the fracture surface, the joints produced at higher welding speeds (200 and $300 \mathrm{~mm} / \mathrm{min}$ ) show characteristic of insufficient reaction, compared with the joints produced at lower welding speeds (100 and $150 \mathrm{~mm} / \mathrm{min})$. As is known, the heat input has direct ratio relations with rotation speeds and inverse ratio with welding speeds during friction stir welding. That is to say, the heat input will decrease with the increasing welding speed when the rotation speed is constant. The insufficient reaction between $\mathrm{Mg}$ alloy and zinc-coated steel is attributed to the insufficient heat input when increasing the welding speed, which leads to the decrease of failure loads of the joints. On the other hand, more heat input at low welding speeds will result in thicker reaction layer, which will deteriorate the mechanical properties of the joints. ${ }^{17}$ ) Therefore, the joints show the maximum failure loads when the welding speed is in appropriate range.

Figure 4 shows a typical transverse cross-section of a joint at the welding speed of $150 \mathrm{~mm} / \mathrm{min}$. It can be seen from this figure that $\mathrm{Mg}$ and steel are joined tightly and the microstructure at side of $\mathrm{Mg}$ is similar to that of FSW of Mg alloy itself. Typical OM micrographs of the BM, the center of the stir zone (SZ), interface and typical re-solidification (the flash in Fig. 2(b)) are indicated in Fig. 5. It can be seen from Fig. 5(a) that the BM of $\mathrm{Mg}$ has a roughly equiaxed grain structure with grain size from $10 \mu \mathrm{m}$ to $15 \mu \mathrm{m}$. Figure $5(\mathrm{~b})$ shows the microstructure in the center of the SZ. The SZ has a coarsened grain structure with grain size from $15 \mu \mathrm{m}$ to
$30 \mu \mathrm{m}$, larger than that in the BM. The grains in the SZ are coarsened by the welding heat cycles during FSW. FSW produces frictional heat at the interface between the tool surface and the welded material. The heat would result in the grain growth of the recrystallized grains in the stir zone. Figure 5(c) shows the microstructure at the interface of $\mathrm{Mg}$ and steel. $\mathrm{Mg}$ and steel are joined tightly and the interface is very thin. Figure 5(d) shows the microstructure of the flash region shown in Fig. 2(b). Typical re-solidification is observed in the clearance between $\mathrm{Mg}$ alloy and zinc-coated steel. The position of the flash is just beyond the domain of the shoulder diameter of the tool.

Figure 6 shows the representative concentration profiles of $\mathrm{Mg}, \mathrm{Zn}$ and $\mathrm{Fe}$ cross the interface in the re-solidification zone shown in Fig. 4 (position D) by a map scanning element analysis. The concentration profiles of $\mathrm{Mg}$ and $\mathrm{Zn}$ detected in the re-solidification zone. There are two kinds of phases in this region, the white substrate (Position A) and the black massive phase (Position B). Quantitative analysis of the chemical compositions by EDS shows that the black massive phase consists of $93.15 \mathrm{at} \% \mathrm{Mg}$ and $6.85 \mathrm{at} \% \mathrm{Zn}$, while substrate contains 67.66 at $\% \mathrm{Mg}$ and 32.34 at\% $\mathrm{Zn}$. This result suggests that the black phase is primary phase of $\mathrm{Mg}$ and the white substrate is $\mathrm{Mg} 7 \mathrm{Zn} 3$.

Figure 7 shows the representative concentration profiles of $\mathrm{Mg}, \mathrm{Al}$ and $\mathrm{Fe}$ cross the interface at the interface shown in Fig. 4 (position $\mathrm{C}$ ). $\mathrm{Zn}$ is not detected and $\mathrm{Al}$ is rich. The result suggests that it is possible that intermetallic compound (IMC) $\mathrm{Al} / \mathrm{Mg}$ or $\mathrm{Al} / \mathrm{Fe}$ forms at the joining interface. The phase structure at the interface is detected using XRD.

Figure 8 shows the X-ray diffraction patterns from fractured surfaces at the sides of $\mathrm{Mg}$ and steel. Diffraction 

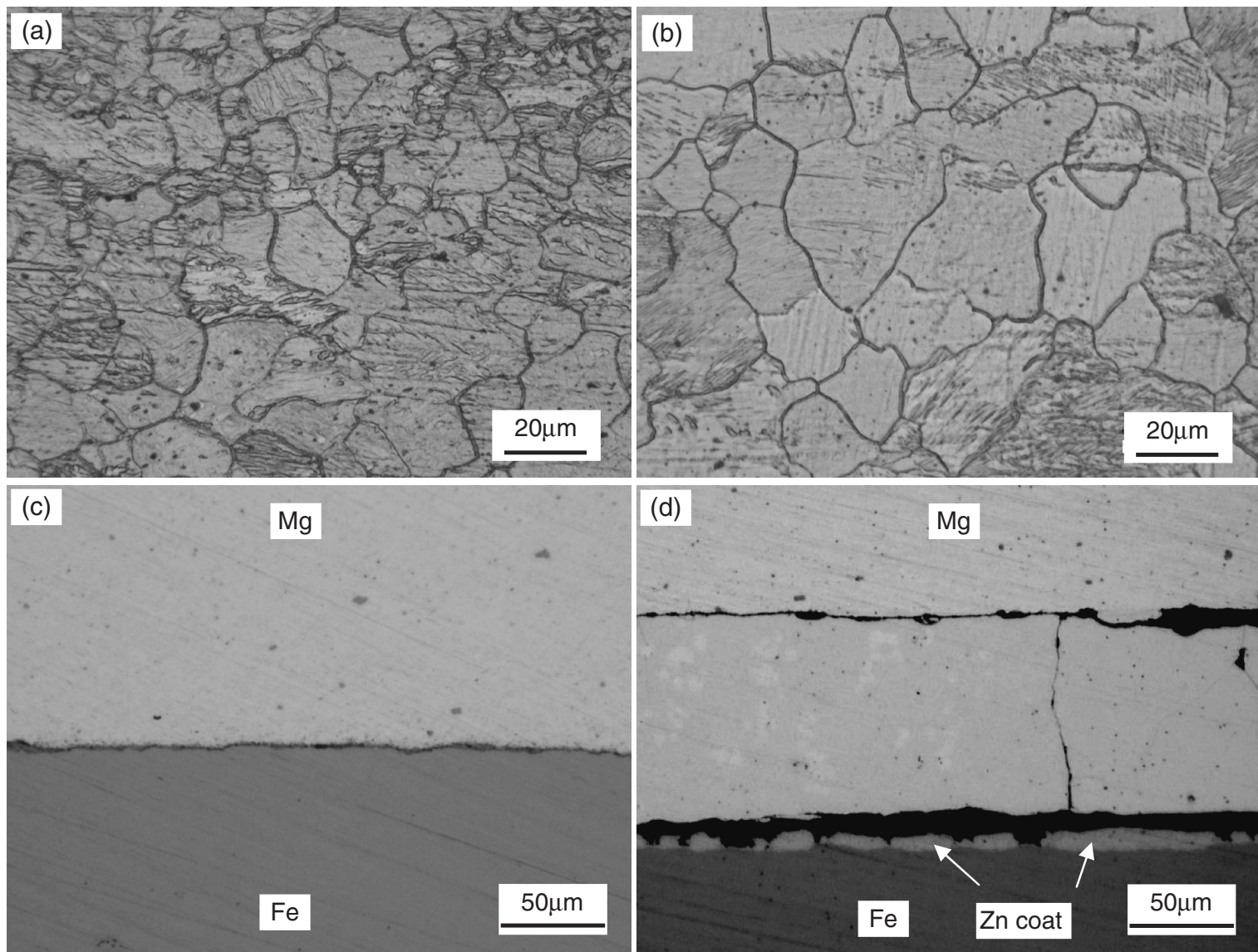

Fig. 5 OM micrographs of different positions shown in Fig. 4. (a) Position A; (b) position B; (c) position C and (d) position D.
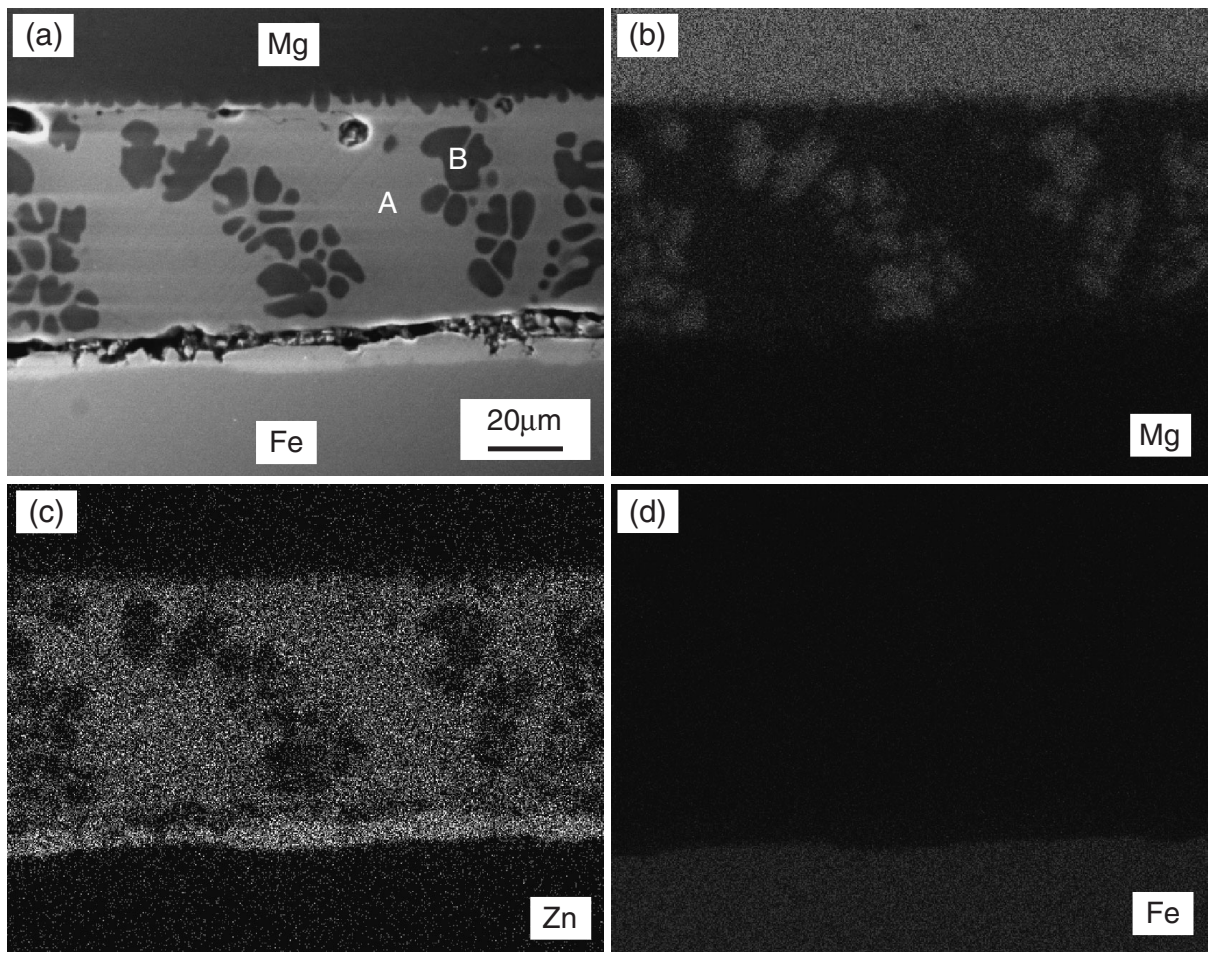

Fig. 6 Qualitative EDS analysis of Position D shown in Fig. 4.

peaks from IMC of Fe4Al13 are detected at the side of steel. At the same time, elements of $\mathrm{Mg}, \mathrm{Fe}$ and $\mathrm{Zn}$ are also found. XRD analysis results from fracture surface show that
Fe4Al13 are the main IMC at the interface. As we know, $\mathrm{Mg}$ and steel do not react with each other. ${ }^{16)}$ The relatively high content of $\mathrm{Al}$ in the $\mathrm{AZ} 31 \mathrm{BM}$ makes it possible to form 

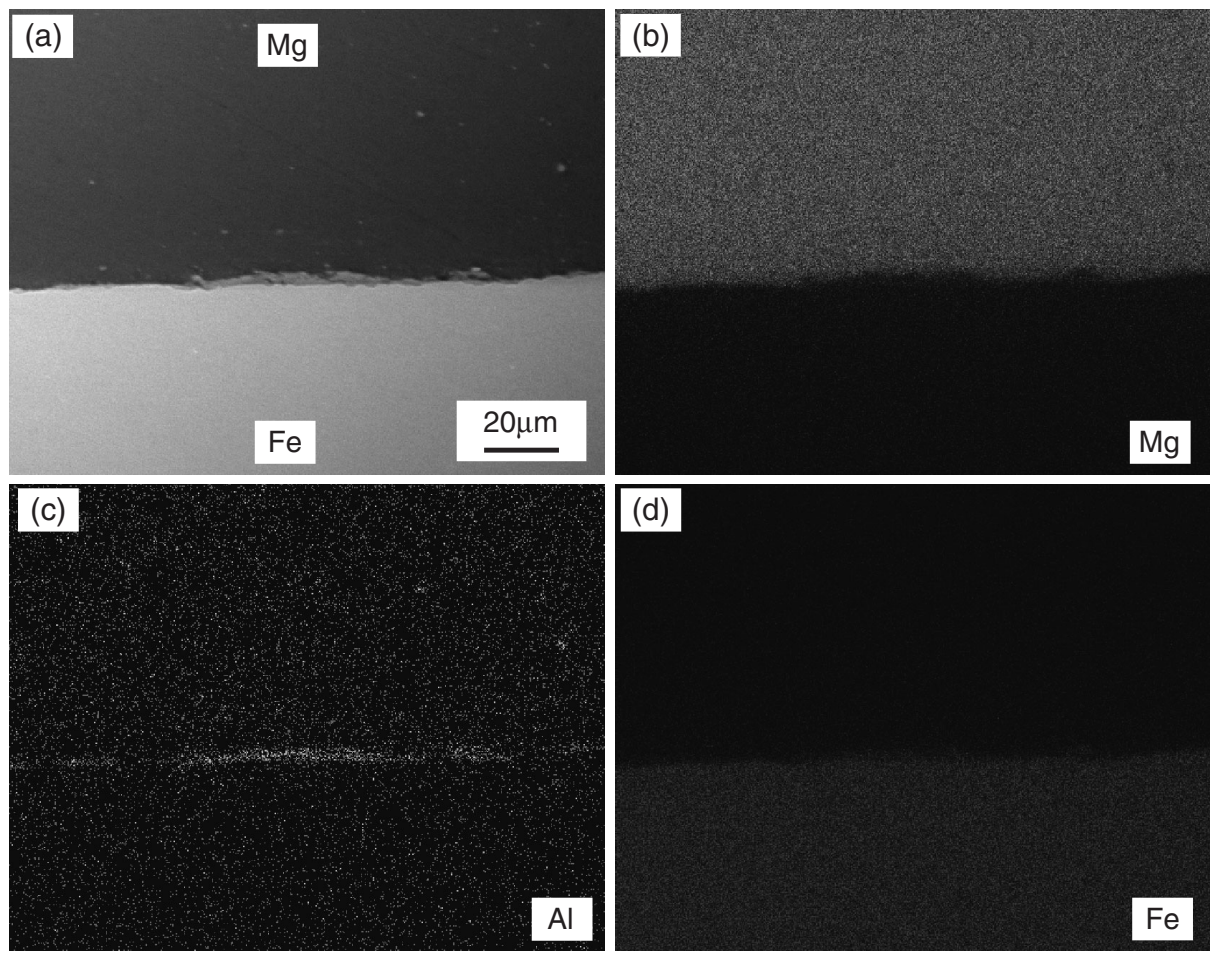

Fig. 7 Qualitative EDS analysis of Position $\mathrm{C}$ shown in Fig. 4.
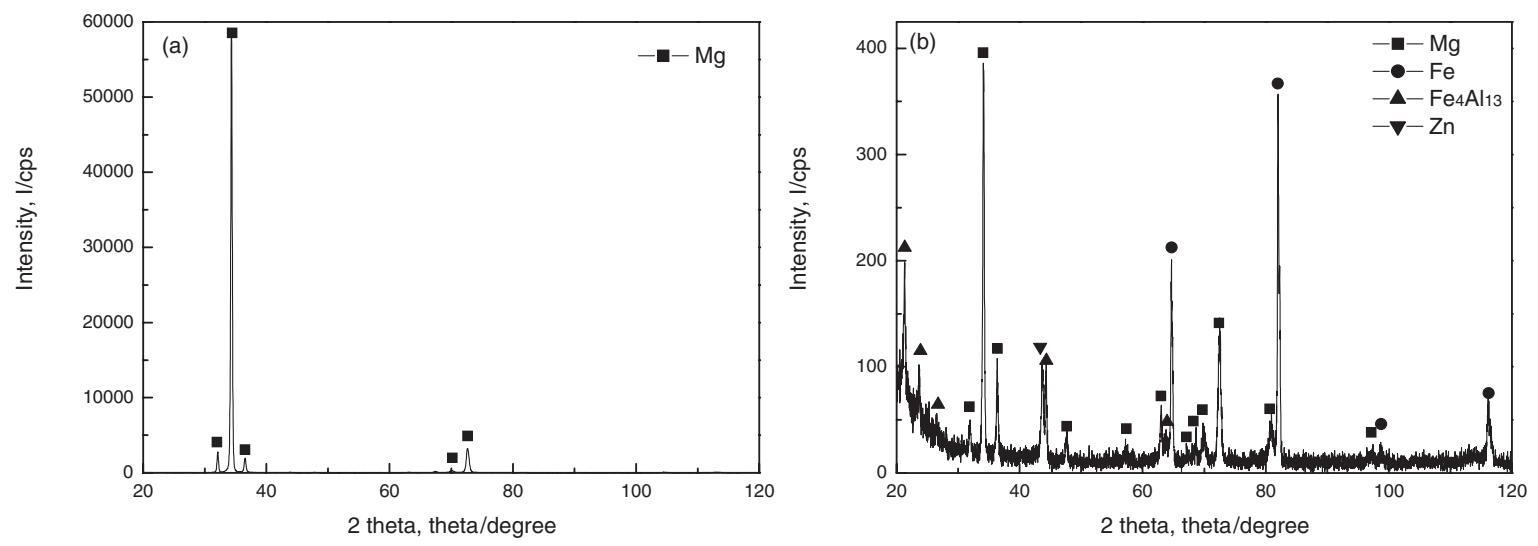

Fig. 8 XRD spectrums from the fracture surface of the joints. (a) Mg side and (b) Fe side.

$\mathrm{Al} / \mathrm{Fe} \mathrm{IMC}$ at $\mathrm{Mg}$ alloy/steel interface. In order to further clarify the joining mechanism, welding heat cycle histories are measured (distance $0 \mathrm{~mm}, 8 \mathrm{~mm}$ and $20 \mathrm{~mm}$ from the weld center at the interface) by an array of K-type thermocouples during welding. It can be seen from the above interface structure analysis that the position of $0 \mathrm{~mm}$ is the interface center (i.e., position $\mathrm{C}$ shown in Fig. 4) and position of $8 \mathrm{~mm}$ is the location of eutectic structure zone (i.e., position D shown in Fig. 4). The welding heat cycle history results are shown in Fig. 9. The peak temperatures at positions of $0 \mathrm{~mm}, 8 \mathrm{~mm}$ and $20 \mathrm{~mm}$ are about $522^{\circ} \mathrm{C}$, $450^{\circ} \mathrm{C}$ and $136^{\circ} \mathrm{C}$, respectively. Such temperatures are lower than the melting points of the base metal of $\mathrm{Mg}$ and $\mathrm{Fe}$ (648 ${ }^{\circ} \mathrm{C}$ and $1538^{\circ} \mathrm{C}$, respectively.), but higher than those of $\mathrm{Zn}$ melting point and $\mathrm{Mg}-\mathrm{Zn}$ eutectic point $\left(420^{\circ} \mathrm{C}\right.$ and $339^{\circ} \mathrm{C}$, respectively.). In other words, the peak temperature in the lap interface center is higher than $\mathrm{Zn}$ melting point

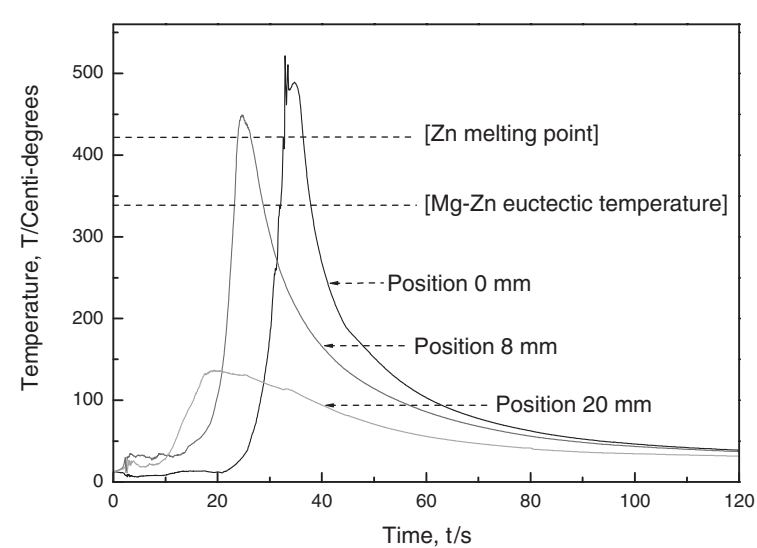

Fig. 9 Welding heat cycle history at different locations (Welding speed of $200 \mathrm{~mm} / \mathrm{min}$ ). 
and $\mathrm{Mg}-\mathrm{Zn}$ eutectic point, which results in the formation of a liquid-phase. Moreover, from the welding heat cycle histories we can know that the dwell time at high temperature above zinc melting point and $\mathrm{Mg}-\mathrm{Zn}$ eutectic point is about $3.6 \mathrm{~s}$ and $5.8 \mathrm{~s}$ in position $0 \mathrm{~mm}$. The dwell time at high temperature above $\mathrm{Mg}-\mathrm{Zn}$ eutectic point is about $5.4 \mathrm{~s}$ in position $8 \mathrm{~mm}$. It means liquid phase can form due to high peak temperature. Furthermore, the high-temperature dwell time is long enough for liquid phase to be pushed aside and filled into the clearance between two sheets. According to the above results, we put forward the following joining mechanism of friction stir lap welding of $\mathrm{Mg}$ alloy and zinc-coated steel. During friction stir welding, the metal in the lap interface undergoes the synthetic effect of the thermal cycle and the mechanical cycle because of the actions of friction, stir and extrusion of the tool. Thus, high temperature and high pressure are generated at the interface. High temperature firstly leads to the melting of pure zinc on the surface of zinc coat and high pressure simultaneously results in the rupture of surface oxide films at both sheets surface, which promotes the formation of lowmelting $\mathrm{Mg}-\mathrm{Zn}$ eutectic reaction products. High pressure then forces the liquid reaction products with broken oxide films and surface contaminants far away from the weld center, which spread along the interface till pile into the natural clearance between two sheets. In this way, the fresh interfaces are exposed and they are tightly extruded together after liquid phase is pushed out. Elements mutual diffusion of $\mathrm{Mg} / \mathrm{Fe}$ and $\mathrm{Al} / \mathrm{Fe}$ occurs, which leads to the formation of a new IMC of Fe4Al13 at the lap interface of the weld. Finally, during the cooling after welding, liquid phase in the natural clearance between two sheets transforms into solid structure.

\section{Conclusions}

AZ31 Mg alloy and zinc-coated steel were lap welded using FSW. The intervention of zinc coat promoted the formation of $\mathrm{Mg}-\mathrm{Zn}$ low-melting-point eutectic structure at the interface. The liquid reaction products with the broken oxide films and surface contaminants were extruded far away from the weld center, spreading along the interface and then piling into the natural clearance between two sheets. This behavior cleared the joining interface and improved significantly the weldability of $\mathrm{Mg}$ alloy and steel.

\section{Acknowledgments}

The authors are very grateful to Mr. Haruki Shingo for his contributory assistance. This work is supported by KAKENHI (17206074), Japan.

\section{REFERENCES}

1) W. M. Thomas, E. D. Nicholas, J. C. Needham, M. G. Murch, P. Templesmith and C. J. Dawes: GB Patent Application No. 9125978.8, December (1991).

2) S. H. C. Park, Y. S. Sato and H. Kokawa: Scr. Mater. 49 (2003) 161.

3) D. Zhang, M. Suzuki and K. Maruyama: Scr. Mater. 52 (2005) 899.

4) A. H. Feng and Z. Y. Ma: Scr. Mater. 56 (2007) 397.

5) C. I. Chang, C. J. Lee and J. C. Huang: Scr. Mater. 51 (2004) 509.

6) W. Woo, H. Choo, D. W. Brown, P. K. Liaw and Z. Feng: Scr. Mater. 54 (2006) 1859

7) A. P. Reynolds, W. Tang, T. Gnaupel-Herold and H. Prask: Scr. Mater. 48 (2003) 1289.

8) C. D. Sorensen, T. W. Nelson and S. M. Packer: Proc. 3rd Int. Symp. on Friction Stir Welding, Kobe, Japan, (2001) CD-ROM.

9) L. Cui, H. Fujii, N. Tsuji and K. Nogi: Scr. Mater. 56 (2007) 637.

10) H. Fujii, L. Cui, N. Tsuji, M. Maeda, K. Nakata and K. Nogi: Mater. Sci. Eng. A 429 (2006) 50.

11) W. M. Thomas, P. L. Threadgill and E. D. Nicholas: Sci. Technol. Weld. Joining 6 (1999) 365.

12) T. J. Lienert, Jr., W. L. Stellwag, B. B. Grimmett and R. W. Warke: Weld. J. 82 (2003) s1.

13) Y. S. Sato, T. W. Nelson, C. J. Sterling, R. J. Steel and C. O. Pettersson: Mater. Sci. Eng. A 397 (2005) 376.

14) Y. S. Sato, H. Yamanoi, H. Kokawa and T. Furuhara: Scr. Mater. 57 (2007) 557.

15) T. Watanabe, K. Kagiya, A. Yanagisawa and H. Tanabe: Q. J. Jpn. Weld. Soc. 24 (2006) 108-115.

16) L. M. Liu and X. Zhao: Mater. Charact. 59 (2008) 1279.

17) Y. C. Chen, T. Komazaki, Y. G. Kim, T. Tsumura and K. Nakata: Mater. Sci. Forum 580-582 (2008) 371. 